\title{
Onset of Presbyopia in a Black Population in Niger-Delta, Nigeria
}

\author{
CS Ejimadu ${ }^{1}, \mathrm{AA}$ Onua ${ }^{1 *}$ and E Ani ${ }^{2}$ \\ ${ }^{1}$ Department of Ophthalmology, University of Port Harcourt Hospital, Nigeria \\ ${ }_{2}^{2}$ The Ophthalmic Specialists Hospital, GRA II, Port Harcourt, Nigeria
}

*Corresponding author: AA Onua, Department of Ophthalmology, University of Port

\section{Abstract}

Background: Presbyopia poses a great challenge in the ocular status among individuals that are heavily dependent on near work for their economic and social activities. The amplitude of accommodation of the human crystalline lens steadily decreases with increasing age and at 35 years of age, the reduction in amplitude causes the near point to move beyond the comfortable reading distance. Studies have shown that the onset of presbyopia varies around the world and among individuals.

Aim: The aim of this study is to determine the time of onset of presbyopia among black population in Port Harcourt, Niger-Delta region of Nigeria.

Methods: This was a hospital-based retrospective study. The case notes of 429 cases diagnosed presbyopia presenting in DDS Eye Centre and Surgery, Port Harcourt between 2006 and 2012 were reviewed. The patients' ages, sexes, occupation, relevant past medical, drugs and ocular history especially when the patients first noticed difficulty in reading tiny prints, recession of near point and the need for brighter illumination or reading as well as family ocular history were retrieved. Data were analyzed with Statistical Package for Social Sciences (SPSS) version 20.

Results: The onset of presbyopia was at the age of 30-34 years in 8.6\% of subjects while $31.2 \%$ of subjects developed presbyopia within the ages of 35 to 39 years. Most of the subjects (39.3\%) developed presbyopia within the ages of 40 and 44 years.

Conclusion: The onset of presbyopia in the Niger-Delta region could be as early as 30 years. Planners and executioners of Eye Care Programs should take advantage of this finding to reach out to increasing population of presbyopes in our locality.

Keywords: Black population; Niger-delta; Onset; Presbyopia

\section{Introduction}

Presbyopia is the decline of the amplitude of accommodation of the human crystalline lens with increasing age; from childhood to 75years of age, when the reduction in amplitude causes the near point to move beyond the comfortable reading distance. Uncorrected presbyopia is a problem worldwide1. There is no racial, ethnic, gender, geographical or social predilection1. Persons and professionals that are engaged in activities that are dependent on near work develop presbyopia earlier. Also, individuals with hypermetropia develop presbyopia earlier than their myopic counterparts. Close to one billion people need near-adds to carry out near tasks such as reading and writing texts [1].

The exact time of the onset of presbyopia is not currently well understood or defined. Different researchers in different parts of the world had estimated the probable time of the onset of presbyopia [2-6]. Donders, et al. stated that presbyopia has its onset at about 45 years of age when the amplitude of accommodation is 3.5 D7. Their investigation on the relationship between amplitude of accommodation and age for a longtime has been the bases for prescribing near add.

Some studies have shown that presbyopia develops earlier in people who live around the equator8-10: In India the age of onset was shown to be 37 years, 39 years in Puerto Rico, 41 years in Israel, 42 years in Japan, 45 years in England, and 46 years in Norway. Further studies show the important variable to be ambient temperature rather than latitude. Thus, the higher the ambient temperature is, the earlier the onset of presbyopia [8-10].

A hospital based prospective study conducted to determine the pattern, age of onset and contributory factors to early onset 
of presbyopia in a major referral center in south western Nigeria 10 years ago however revealed that $15.5 \%$ of the patients had presbyopia before age 40 years: The youngest age of presentation being 33 years [11]. In that study Bernice and Soetan concluded that Presbyopia sets in much earlier in Nigerians and that increased visual activity is a major contributing factor [11].

Presbyopia is receiving growing attention because of the recognition that good near vision is needed to accomplish a broad range of tasks, not only reading and writing, Ilesh Patel and Sheila $\mathrm{K}$ West in their work in Tanzania, for example discovered that women used near vision for lighting and adjusting lamps, winnowing grain, sorting rice, weeding, sewing, cooking food, and dressing children [5]. Men reported using near vision for lighting and adjusting lamps, reading, writing, harvesting, and weeding. Early diagnosis and prescription of adequate near add will go a long way to improve the quality of life of persons with earlier onset of presbyopia. This study is aimed at establishing the age of onset of presbyopia amongst patients seen in ophthalmic clinic in Port Harcourt, a city in Niger Delta region of Nigeria.

\section{Material and Methods}

This was a hospital-based retrospective study. The case notes of all the 429 cases of presbyopia diagnosed in DDS Eye Centre and Surgery, Port Harcourt between 2006 and 2012 were reviewed. The patients' ages, sexes, occupation, relevant past medical, drugs and ocular history especially when the patients first noticed difficulty in reading tiny prints, recession of near point and the need for brighter illumination for reading as well as family ocular history were retrieved. Data were analyzed with Statistical Package for Social Sciences (SPSS) version 20. Each subject's case note was checked to exclude persons having any systemic, neurologic, and ocular disease or taking any drugs and medications that could compromise accommodation. The case notes revealed that study subjects had proper ophthalmic examinations (anterior segment with a pen torch and slit lamp bio microscope and posterior segment evaluation with Welch Allen ophthalmoscope). Objective refractions were done with streak retinoscope and then subjectively refined. Each had corrected distance and near visual acuity of $6 / 6$ and $\mathrm{N} 5$ respectively or better and normal binocularity. Full distance correction was worn during all testing. Pre-sbyopic condition was clinically defined here as the inability of an individual to read N6 optotype with full distance correction and if they were able to read at least one more line with the addition of a plus lens. Those who had difficulty reading tiny prints especially in dim illumination, with receding near point and whose near vision were corrected to at least N6 were recruited into the study. Data were analyzed with Statistical Package for Social Sciences (SPSS) version 20.

\section{Consent and Ethical Approval}

As per international standard and university standard, patients' written consent has been collected and preserved by the authors. The authors obtained informed consent, protection of privacy from the participants of this study.

\section{Results}

Table 1: Age and Gender Distribution of the Study Population.

\begin{tabular}{|c|c|c|c|c|}
\hline $\begin{array}{l}\text { Age Group } \\
\text { (Years) }\end{array}$ & Male (\%) & Female (\%) & Total (\%) & P-Value \\
\hline $30-34$ & $20(4.7)$ & $18(4.2)$ & $38(8.9)$ & \multirow{6}{*}{1} \\
\hline $35-39$ & 78 (18.2) & $60(14.0)$ & $138(32.2)$ & \\
\hline $40-44$ & 93 (21.7) & 81 (18.9) & $174(40.5)$ & \\
\hline $45-49$ & $39(9.1)$ & $26(6.1)$ & $65(15.1)$ & \\
\hline $50 \&$ Above & $8(1.9)$ & $6(1.4)$ & $14(3.3)$ & \\
\hline Total & $238(55.5)$ & $191(44.5)$ & $429(100)$ & \\
\hline
\end{tabular}

Table 1 Shows a total of 429 subjects who participated in the study, 238 were males and 191 females. The difference between the ages of the study population and their respective genders was not statistically significant $(\mathrm{p}=1.000)$.

Table 2: Correlation between onset of presbyopia and gender in the study population.

\begin{tabular}{|c|c|c|c|}
\hline \multirow{2}{*}{ Onset (Years) } & \multicolumn{2}{|c|}{$\operatorname{sex}$} & \multirow{2}{*}{ Total } \\
\hline & Male & Female & \\
\hline 30 & $2(100)$ & $0(0.0)$ & $2(0.5)$ \\
\hline 31 & $3(50)$ & $3(50)$ & $6(1.4)$ \\
\hline 32 & $3(60)$ & $2(40)$ & $5(1.1)$ \\
\hline 33 & $4(50)$ & $4(50)$ & $8(108)$ \\
\hline 34 & $8(47.1)$ & $9(52.9)$ & $17(3.8)$ \\
\hline 35 & $10(52.6)$ & $9(47.4)$ & $19(4.3)$ \\
\hline 36 & $11(47.8)$ & $12(52.2)$ & $23(5.2)$ \\
\hline 37 & $12(57.1)$ & $9(42.9)$ & $21(4.7)$ \\
\hline 38 & $21(61.8)$ & $13(38.2)$ & $34(7.7)$ \\
\hline 39 & $24(58.5)$ & $17(41.5)$ & $41(9.3)$ \\
\hline 40 & $22(56.4)$ & $17(43.6)$ & $39(8.8)$ \\
\hline 41 & $23(56.1)$ & 18(43.9) & $41(9.3)$ \\
\hline 42 & $15(45.5)$ & $18(54.5)$ & $33(7.4)$ \\
\hline 43 & $17(45.9)$ & $20(54.1)$ & $37(8.4)$ \\
\hline 44 & $16(66.7)$ & $8(33.3)$ & $24(5.4)$ \\
\hline 45 & $12(54.5)$ & $10(45.5)$ & $22(5)$ \\
\hline 46 & $6(60)$ & $4(40)$ & $10(2.3)$ \\
\hline 47 & $5(62.5)$ & $3(37.5)$ & $8(1.8)$ \\
\hline 48 & $9(64.3)$ & $5(35.7)$ & $14(3.2)$ \\
\hline 49 & $7(63.6)$ & $4(36.4)$ & $11(2.5)$ \\
\hline 50 & $4(66.7)$ & $2(33.3)$ & $6(1.4)$ \\
\hline 51 & $4(50)$ & $4(50)$ & $8(1.8)$ \\
\hline Total & $238(55.8)$ & $191(44.2)$ & $429(100)$ \\
\hline
\end{tabular}

Chi-square $=9.40 ; P$-Value $=0.991(p>0.05)$

Table 2 also shows that $8.6 \%$ of subjects had presbyopia within the age range of 30 to 34 years, while $31.2 \%$ of subjects developed presbyopia within the ages of 35 to 39 years. There was no satistical difference in the age of onset or progression of presbyopia between male and female patients ( $p>0.05)$.

\section{Discussion}

In this study, four hundred and twenty-nine persons were recruited as study-participants. There was a male preponderance 
of $55.5 \%$. The age range was 30 to 51 years. The difference between the ages of the study population and their respective genders was not statistically significant $(\mathrm{p}=1.000)$ Table 1 . This observation is at variance with our earlier study where there was a higher proportion of females with presbyopia [12]. Also, different studies in various parts of the world had reported female preponderance in the prevalence of presbyopia $[3,13]$. Pointer, in his clinic-based study, noted that presbyopia affected women earlier than their male counterparts [14]. The explanation of these differences in gender preponderance needs further investigation.

Age is one of the core determinants of the onset of presbyopia correction. Other factors that could influence the onset of presbyopia in individuals are occupation, hobby and type of refractive error especially hypermetropia. This study sets out to determine the age of onset of presbyopia among clients attending DDS Eye Centre and Surgery in the outskirt of Port Harcourt, Rivers State in the Niger Delta region of Nigeria. In this study, $8.6 \%$ of subjects had presbyopia within the age range of 30 to 34 years, while $31.2 \%$ of subjects developed presbyopia within the ages of 35 to 39 years. The youngest subjects with presbyopia were 30 years old, the number of subjects with presbyopia increased with increasing age but reduced after the age of 41 years. Most of the subjects (39.3\%) developed presbyopia within 40 to 44 years. It was observed that the onset of presbyopia was at the age of 30 years Table 2. This observation corroborates with our earlier study where the onset of presbyopia among 836 residents of Port Harcourt was found to be 31years. The population studied in the two instances were from the same locality and probably some study subjects with identical socio-demographic characteristics were blindly recruited in both studies. Also, some studies in hospital patients in Africa showed a younger onset of presbyopia than studies conducted in Europe and North America [15-17]. However, many researchers differ as to the age of onset of presbyopia; other researches have noted the age of onset of presbyopia between 30 and 40 years [18]. Several studies have correlated geographical variations in the age of onset of presbyopia with latitude and climate; hotter climates are associated with earlier onset of presbyopia [8-10]. However, occupation/ profession, ethnicity, race, climate and geographical location could also be confounding factors and the specific influence of these factors ought to be independently investigated.

In this study, it was noted that there was no correlation between the age of onset of presbyopia and gender. Table 2, There was no significant difference in the age of onset or progression of presbyopia between male and female patients ( $p>0.05)$. This finding, however, need further investigation.

\section{Conclusion}

The onset of presbyopia among the people of Niger Delta region of Nigeria could be as early as 30 years and planning of Eye Care
Services should therefore put this into consideration. Geographical location of clients in the influence of the onset of presbyopia should be considered as a major contributory factor.

\section{Acknowledgement}

None.

\section{Conflict of Interest}

The authors hereby declare that there is no conflict of interest.

\section{References}

1. Holden BA, Fricke TR, Ho SM, Wong R, Schlenther G, et al. (2008) Global vision impairment due to uncorrected presbyopia. Arch Ophthalmol 126(12): 1731-1739.

2. Ilesh P, Sheila W (2009) Gender differences in presbyopia. Community Eye Health 22(70): 27.

3. Hickenbotham A, Roorda A, Steinmaus C, Glasser A (2012) Meta-analysis of sex differences in presbyopia. Invest Ophthalmol Vis Sci 53(6): 3215-3220

4. Burke AG, Patel I, Munoz B, Kayongoya A, McHiwa W, et al. (2006) Population-based study of presbyopia in rural Tanzania. Ophthalmology113(5): 723-727.

5. Patel I, Munoz B, Burke AG, Kayongoya A, McHiwa W, et al. (2006) Impact of presbyopia on quality of life in a rural African setting. Ophthalmology 113(5): 728-734.

6. Prevention of Blindness and Deafness (2001) Elimination of avoidable visual disability due to refractive errors. Report of an informal planning meeting Geneva, 3-5 July 2000. Geneva. WHO, Geneva, pp.8-9.

7. Weale RA (2003) Epidemiology of refractive errors and presbyopia. Surv Ophthalmol 48(5): 515-543.

8. Miranda MN (1979) The geographic factor in the onset of Presbyopia. Trans Am Ophthalmol Soc 77: 603-621.

9. Rambo VC (1953) Further notes on the varying ages at which different people develop presbyopia. Am J Ophthalmol 36(5): 709-710.

10. Bernice O, Soetan EO (2006) Risk factors for early presbyopia in Nigerians. Nigerian Journal of Surgical Sciences 16(1): 7-11.

11. Ejimadu CS, Onua AA, Ani E (2017) Evaluation of Presbyopia in a peripheral Eye Clinic in Port Harcourt, Nigeria. JAMMR 22(6): 1-6.

12. Ilesh P, Sheila W (2007) Presbyopia: Prevalence, impact and interventions. Community Eye Health 20(63): 40-41.

13. Pointer JS (1995) The Presbyopic add: Age-related trend and gender difference. Ophthalmic Physiol Opt 15(4): 241-248.

14. Coveli LL (1950) Presbyopia. Am J Ophth 33: 1275-1276.

15. Adefule AO, Valli NA (1983) Presbyopia in Nigerians. East Afr Med J 60(11): 766-772.

16. Kaimbo K, Maertens K, Missotten L (1987) Study of Presbyopia in Zaire. Bull Soc Belge Ophthalmol 225: 149-156.

17. Duarte WR, Barros AJ, Dias-da-Costa JS, Cattan JM (2003) Prevalence of near vision deficiency and related factors: A population-based study. Cad Saude Publica 19(2): 551-559.

18. Nirmalan PK, Krishnaiah S, Shamanna BR, Rao GN, Thomas R (2006) A population-based assessment of presbyopia in the state of Andhra Pradesh, South India:The Andhra Pradesh Eye Disease Study. Invest Ophthalmol Vis Sci 47(6): 2324-2328. 